\title{
PERCEPÇÃO DOS CLIENTES DE UM SALÃO DE BELEZA SOBRE OS DETERMINANTES DA SATISFAÇÃO E ATRIBUTOS DE QUALIDADE OFERTADOS
} PERCEPTION OF CUSTOMERS IN A BEAUTY SALON ABOUT THE DETERMINANTS OF SATISFACTION AND QUALITY ATTRIBUTES OFFERED

\author{
Recebido em 16.09.2020 Aprovado em 23.11.2020 \\ Avaliado pelo sistema double blind revien \\ DOI: https://doi.org/10.32888/cge.v8i3.46274
}

Thales Cardoso Lafetá

thalescardosop@yahoo.com

UNIFIPMOC - Centro Universitário FipMoc/Graduação em Publicidade e Propaganda - Montes Claros/MG

Hemilly Karolyne Ramos de Souza

hemillykarolyne@gmail.com

UNIFIPMOC - Centro Universitário FipMoc/Graduação em Publicidade e Propaganda - Montes Claros/MG 0000-0002-4133-0394

\section{Andréa Nogueira do Amaral Ferreira}

deiaamaral11@hotmail.com

UNIFIPMOC - Centro Universitário FipMoc/Graduação em Publicidade e Propaganda - Montes Claros/MG 0000-0002-2644-3542

\author{
Gustavo Souza Santos \\ gustavo.ccpv@gmail.com \\ UNIFIPMOC - Centro Universitário FipMoc/Graduação em Publicidade e Propaganda - Montes Claros/MG \\ UNIMONTES - Universidade Estadual de Montes Claros/Doutorado em Desenvolvimento Social - Montes \\ Claros/MG, Brasil \\ CEAD/Unimontes - Centro de Educação à Distância da Unimontes - Montes Claros/MG, Brasil \\ 0000-0002-9712-2690

\section{Josiane Santos Brant Rocha} \\ josianenat@yahoo.com.br \\ UnB - Universidade de Brasilia/Doutorado em Ciências da Saúde - Brasilia/DF, Brasil \\ UCB - Universidade Católica de Brasília/Mestrado em Educação Física - Brasília/DF, Brasil \\ CEAD/Unimontes - Centro de Educação à Distância da Unimontes - Montes Claros/MG, Brasil \\ UNIFIPMOC - Centro Universitário FipMoc/Graduação em Publicidade e Propaganda - Montes Claros/MG \\ 0000-0002-7317-3880
}

\section{Resumo}

Este estudo tem por objetivo apresentar os determinantes da satisfação dos clientes de um salão de beleza e identificar os atributos de qualidade percebidos por eles. Para tal foi realizada uma pesquisa quantitativa e descritiva, por meio da aplicação de questionários aos consumidores. Os atributos foram avaliados de acordo à sua importância. Observou-se que os principais atrativos abordam estacionamento, entretenimento, uniformes, atualização de tendências, empatia e conveniência de horários. Os dados dessa pesquisa podem ser utilizados por administradores de salões de beleza para elevar a qualidade do serviço e a satisfação do público, estabelecendo um diferencial competitivo para sua marca.

Palavras-chave: Qualidade. Salões de beleza. Diferencial competitivo.

\begin{abstract}
This study aims to present the determinants of customer satisfaction in a beauty salon and to identify the quality attributes perceived by them. To this end, a quantitative and descriptive survey was conducted, through the application of questionnaires to consumers. The attributes were evaluated according to their importance. It was observed that the main attractions address parking, entertainment, uniforms, updating trends, empathy and convenience of schedules. The data from this survey can be used by beauty salon administrators to increase the quality of service and public satisfaction, establishing a competitive differential for their brand.
\end{abstract}

Keywords: Quality. Beauty salons. Competitive differential. 


\section{Introdução}

O setor de perfumaria e cosméticos acumula cada vez mais força. Segundo Ros (2016) este setor pertence à indústria química, que contempla a manipulação de fórmulas destinadas a alterar aspectos naturais e realçar a beleza, sejam elas para corpo, rosto ou cabelo.

Dentre as indústrias de cosméticos alguns segmentos se destacam, como os salões de beleza que representam uma prestação de serviços crescente, segundo dados recém-divulgados pela Associação Brasileira da Indústria de Higiene Pessoal, Perfumaria e Cosméticos (ABIHPEC). Os dados revelam que nos últimos cinco anos, o mercado de estética cresceu 567\% no Brasil.

Entretanto, a concorrência neste mercado tem sido acirrada, tornando importante considerar aspectos como: atualizar-se sobre novas técnicas, proporcionar ao cliente produtos de qualidade e dispor de equipamentos modernos. Para Saab et al. (2001), diversas estratégias podem ser adotadas quando se pretende aumentar o número de clientes, sendo fundamental o treinamento dos funcionários e a adoção de medidas de fidelização.

Segundo Ribeiro et al. (2011), os administradores de salão de beleza precisam gerenciar gastos com introdução de qualidade nos serviços, sofisticação de ambiente e equipamentos, pois são serviços que exigem maior personalização. Já Ros (2016), considera que um elemento importante no processo de concorrência é a inovação.

Frente aos pressupostos apresentados, o objetivo deste estudo é caracterizar os determinantes da satisfação dos clientes e identificar os atributos de qualidade percebidos para os serviços ofertados por um salão de beleza de Montes Claros - Minas Gerais.

\section{Satisfação dos Clientes}

Silva e Saraiva (2012) apontam que o maior acesso à informação tem produzido consumidores cada vez mais exigentes. O conceito de qualidade torna-se mais amplo, englobando não apenas o serviço ofertado mas também o atendimento, forma de entrega e benefícios secundários do produto ou serviço.

Essa exigência dos clientes aliada ao aumento expressivo da concorrência, obriga os profissionais e empresas do ramo a buscarem formas de se diferenciar no mercado e fidelizar o público. Para isso é fundamental conhecer as necessidades e prioridades do consumidor, analisar a abordagem atual e modificá-la implantando estratégias bem delineadas. (SILVA; SARAIVA, 2012)

Segundo Tinoco e Ribeiro (2007) a avaliação dessas características se torna complexa porque os benefícios psicológicos não são facilmente mensuráveis, principalmente quando se aborda a prestação de serviços, por sua natureza intangível. Mesmo complexa, essa aferição se prova essencial pela criação de índices nacionais de satisfação do consumidor em diversos países.

Para Silva e Saraiva (2012) a satisfação está diretamente atrelada às expectativas e à superação das mesmas. Se o serviço não corresponde à ideia construída no imaginário do cliente, as expectativas são frustradas e consequentemente a perceção de qualidade é reduzida. Em situação oposta, se além de suprir as expectativas a empresa for capaz de entregar um elemento surpresa, o consumidor não apenas entrará na fase de satisfação, mas também de admiração, o que desencadeará o processo de fidelização. (SILVA; SARAIVA, 2012)

Ribeiro, Thiesen e Tinoco (2012) defendem que a satisfação é a principal responsável pela lealdade do cliente à empresa e consequentemente pela construção das relações de longo prazo. Preservar esses clientes satisfeitos demanda menos esforço do que conquistar novos consumidores, ao mesmo tempo que colabora com a propagação 
da marca, por meio do popular "boca a boca". (BATESON; HOFFMAN, 2001 apud RIBEIRO; THIESEN; TINOCO, 2012)

\section{Procedimentos metodológicos}

Esta pesquisa foi caracterizada como estudo quantitativo, descritivo, realizado em um salão de beleza localizado na cidade de Montes Claros, norte de Minas Gerais, no período de agosto a outubro de 2019. A população do estudo foi constituída por clientes frequentadores do salão por no mínimo seis meses.

A coleta de dados ocorreu nas dependências da empresa, por meio de um questionário validado por Ribeiro, Thiesen e Tinoco (2011), o qual foi adaptado à realidade do estudo. As questões abordadas no questionário referiam-se a informações sobre as qualidades e atributos necessários a um salão de beleza para a satisfação dos clientes.

As questões foram divididas em 4 grupos, sendo o primeiro referente à estrutura do salão e abordando as seguintes variáveis: disponibilidade de estacionamento; disponibilidade de entretenimento (revistas, TV, etc.); ambiente que assegura privacidade; banheiro confortável; disponibilidade de água, chá, ou café; conforto acústico e som ambiente; ambiente climatizado; móveis confortáveis; e sala de espera agradável.

O segundo grupo referiu-se aos funcionários e pesquisou as seguintes variáveis: utilização de uniforme; atualização com as tendências; experiência; respeito com o tempo de realização de serviços; competência técnica; compromisso com horários marcados; e higienização e individualização de utensílios.

O terceiro grupo tratou da interação cliente/funcionário e verificou as seguintes variáveis: entendimento das necessidades do cliente; discrição (não falar dos outros clientes); esclarecimento do serviço a ser realizado; atenção individual/tratamento personalizado; exatidão do serviço realizado; cortesia; e vontade de ajudar.

Por fim, o último grupo contemplou os serviços ofertados e considerou as seguintes variáveis: horários convenientes de atendimento; possibilidade de marcar horário; variedade de serviços; segurança; variedade de produtos e marcas; boa interação social com outros clientes; público agradável que frequenta o salão; limpeza do ambiente; equipamentos e utensilios modernos; e recepção agradável.

Foi solicitado aos entrevistados que marcassem no questionário os 3 (três) itens mais importantes de cada categoria, considerando o seu ponto de vista e assinalando 1 para o item mais importante, 2 para o segundo e 3 para o terceiro item (menos importante).

A pesquisa foi aplicada após o aceite dos convidados e assinatura do termo de consentimento livre e esclarecido. Após a coleta os questionários foram devidamente organizados pelo pesquisador, tabulados em planilha do Microsoft Excel e posteriormente exportados para o programa SPSS, versão 21, onde se realizou uma análise descritiva das variáveis investigadas, pontuando frequências e porcentagens.

\section{Apresentação e análise dos resultados}

A amostra final foi constituída por 98 clientes, entretanto, apenas 92 questionários estavam devidamente preenchidos. Ao analisar a tabela 1 que aborda critérios de estrutura, observou-se que a disponibilidade de estacionamento é um dos itens mais importantes, correspondendo a 58,7\% dos entrevistados. Em seguida, disponibilização de entretenimento (revistas, TV) ocupa o segundo lugar, eleito por $42,4 \%$ da amostra. E para $33,8 \%$ das entrevistadas é necessário um ambiente que assegure privacidade. 
Tabela 1 - Análise descritiva relativa aos atributos de qualidade percebidos pelos clientes do salão de beleza, considerando a estrutura do salão.

\begin{tabular}{lcc}
\hline \multicolumn{1}{c}{ Tabela 1 - ESTRUTURA DO SALÃO } & & \\
\hline \multicolumn{1}{c}{ Variáveis } & N & $\%$ \\
\hline Disponibilidade de Estacionamento & 54 & 58,7 \\
Disponibilidade de Entretenimento (revistas, TV, etc) & 39 & 42,4 \\
Ambiente que assegure privacidade & 21 & 33,8 \\
Banheiro Confortável & 30 & 32,6 \\
Disponibilidade de água, chá ou café & 24 & 26 \\
Conforto acústico e som ambiente & 22 & 24 \\
Ambiente climatizado & 20 & 21,8 \\
Móveis confortáveis & 20 & 21,8 \\
Sala de espera agradável & 17 & 18,5 \\
\hline
\end{tabular}

Fonte: dados da pesquisa (2019).

Mendonça e Oliveira (2008) apontam que estrutura física se destaca como fator de impacto sobre as percepções dos clientes, pois transmitem características de qualidade em relação aos serviços e criam expectativas, podendo inclusive, incentivar a busca pelo serviço. Neste cenário, disponibilizar estacionamento foi um item de grande relevância, uma vez que concede conforto e comodidade para a clientela.

O cenário dos serviços pode aproximar ou afastar o acesso, pois influencia a forma como os clientes vêm os serviços oferecidos, bem como influenciam a natureza e a qualidade das interações sociais. (MENDONÇA; OLIVEIRA, 2008 apud BITNNER, 1992) Assim, inclui-se a disponibilização de entretenimento e a oferta de um ambiente confiável.

Venâncio et al. (2013) ao citar Santos et al. (2007) corrobora a ideia de que os clientes dão maior importância a aspectos como higiene e limpeza, estacionamento e aparência dos equipamentos.

Ribeiro et al. (2011) afirma que nos salões de beleza, há uma procura por revistas de celebridades. Estas revistas são usadas como critério para o serviço procurado, ou seja, desejam o que é usado por celebridades e anseiam que o estabelecimento atenda este desejo. 
Tabela 2 - Análise descritiva relativa dos atributos de qualidade percebidos pelos clientes do salão de beleza, considerando os funcionários.

\begin{tabular}{llcl}
\hline \multicolumn{1}{c}{ Tabela 2 - FUNCIONÁRIOS } & & \\
\hline \multicolumn{1}{c}{ Variáveis } & $\mathbf{N}$ & $\%$ \\
\hline Utilização de uniforme & 68 & 74 \\
Atualização com as tendências & 52 & 56,53 \\
Experiência & 39 & 42,4 \\
Respeito com o tempo de realização do serviço & 38 & 41,3 \\
Competência técnica & 29 & 31,5 \\
Compromisso com horários marcados & 23 & 25 \\
Higienização e individualização de utensílios & 12 & 13,04 \\
\hline
\end{tabular}

Fonte: dados da pesquisa (2019).

Ao analisar a tabela 2 que se refere aos recursos humanos da empresa, pode-se perceber que $74 \%$ das entrevistadas consideram a utilização de uniforme importante no que tange a satisfação do cliente. $56,53 \%$ consideram importante a atualização de tendências e $42,4 \%$ acreditam que a experiência profissional é um critério importante na escolha de um espaço para cuidar da beleza.

De acordo com Silva (2011), o mercado é bastante competitivo e as empresas precisam ser criativas para conquistar a preferência dos clientes. Desta maneira, observa-se que os consumidores estão cada vez mais atentos ao adquirir um produto ou serviço.

Com relação aos funcionários Ribeiro et al (2011) cita a importância do uniforme e, além disso, da postura profissional, conhecimento, experiência, disponibilidade de ajudar e comprometimento para cumprir os horários agendados.

O uniforme traz conforto, segurança, praticidade e imagem corporativa. O seu uso pode promover a presteza das atividades, melhorando a circulação e diminuindo o deslocamento para busca de utensílios, o que agiliza a atividade. (RIBEIRO et al 2009, apud LIMA et al. 2009)

Para se manter no mercado, é primordial estar atento às tendências. Ribeiro (2011) defende que o funcionário precisa atualizar-se continuamente, com os novos costumes e tipos de serviço. No momento de escolha ou troca do salão de beleza que frequenta, a eficiência, a habilidade e a técnica dos funcionários são categóricos. 
Tabela 3 - Análise descritiva relativa dos atributos de qualidade percebidos pelos clientes do salão de beleza, considerando interação cliente/funcionário.

\begin{tabular}{lcc}
\hline Tabela 3 - INTERAÇÃo CLIENTE/FUNCIONÁRIO & & \\
\hline \multicolumn{1}{c|}{ Variáveis } & $\mathbf{N}$ & $\mathbf{\%}$ \\
\hline Entendimento das necessidades do cliente & 41 & 44,6 \\
Discrição (não falar de outros clientes) & 41 & 44,6 \\
Esclarecimento do serviço a ser realizado & 36 & 39,1 \\
Atenção individual/tratamento personalizado & 34 & 37 \\
Exatidão do serviço realizado & 34 & 37 \\
Cortesia & 33 & 35,8 \\
Vontade de ajudar & 22 & 24 \\
\hline Fonte: dados da pesquisa (2019).
\end{tabular}

Fonte: dados da pesquisa (2019).

Ao analisar as variáveis de interação cliente-funcionário destaca-se que a frequência de importância para os itens listados é muito próxima, com exceção ao item vontade de ajudar, que se revelou menos relevante. Constata-se então que as clientes esperam funcionários antenados às suas reais necessidades (44,6\%), que atuem de forma discreta $(44,6 \%)$ e esclareçam sobre o serviço a ser realizado (39,1\%), prestando um atendimento individualizado (37\%) e um serviço exatamente conforme ofertado $(37 \%)$.

Desta maneira, Venâncio et al. (2013) pontua que prestar serviços de qualidade e com rapidez tem se tornado um desafio diário nos salões de beleza, os quais não comercializam apenas serviços, mas muitas vezes, "sonhos". Entretanto, para que os sonhos não sejam destruídos, é imprescindível ter consciência da qualidade do serviço que se presta. Assim suprindo as necessidades dos consumidores.

A qualidade é avaliada pelo consumidor por meio da comparação entre suas expectativas e a percepção que ele obteve do desempenho do serviço. Neste mesmo raciocínio, o desafio da qualidade em serviços é que ela seja examinada pelos clientes, ou seja, a qualidade é compreendida como boa quando o cliente percebe que suas expectativas estão de acordo com produto final. (VENÂNCIO et al. 2013) Assim, um bom esclarecimento do serviço a ser realizado é de extrema importância, bem como o tratamento especializado. 
Tabela 4 - Análise descritiva relativa aos atributos de qualidade percebidos pelos clientes do salão de beleza, considerando os serviços ofertados.

\begin{tabular}{lcc}
\hline \multicolumn{1}{c}{ Tabela 4 - SERVIÇOS OFÉveis } & N & \\
\hline \multicolumn{1}{c}{ Vorados } & 39 & $\%$ \\
\hline Horários convenientes de atendimento & 35 & 42 \\
Possibilidade de marcar hora & 33 & 38 \\
Variedade de serviços & 31 & 35,8 \\
Segurança & 31 & 33,7 \\
Variedade de produtos e marcas & 29 & 33,7 \\
Boa interação social com outros clientes & 28 & 31,5 \\
Público agradável que frequenta o salão & 23 & 30,4 \\
Limpeza do ambiente & 22 & 25 \\
Equipamentos e utensílios modernos & 20 & 24 \\
Recepção agradável & 15 & 21,7 \\
Reconhecimento de clientes assíduos e suas preferências & & 16,03 \\
\hline
\end{tabular}

Fonte: dados da pesquisa (2019).

A tabela 4 retrata o comprometimento da empresa com o cliente e o quanto as entrevistadas consideram este fator importante ao escolher um serviço.

Hoffman e Bateson (2006) pontuam que há cinco dimensões da qualidade do serviço, que atendem às necessidades dos clientes e são medidas da seguinte forma:

A primeira dimensão é onde o cliente avalia a gestão dos tangíveis em volta do serviço prestado, sejam os equipamentos e instalações, sejam o pessoal e os meios de comunicação.

O segundo ponto é a credibilidade, sendo esta a dimensão mais importante, pois reflete a consistência e a confiança que uma empresa inspira. Nesta dimensão verifica-se até que ponto um bem ou serviço não varia sua qualidade toda vez que é executado.

$\mathrm{Na}$ terceira dimensão enquadra-se o atendimento, ou seja, a disponibilidade dos funcionários em conjunto com a formação dos mesmos para atender os clientes, refletindo diretamente no compromisso da empresa de fornecer seus serviços.

A quarta dimensão diz respeito à segurança nas operações com a organização, bem como a capacidade do profissional é demonstrada e a cortesia oferecida.

A quinta e última dimensão aborda a empatia, ou seja, entender o desejo do outro como se fosse nosso, perceber as sensações como sendo o cliente. A organização que atinja com sucesso esta dimensão terá um diferencial no mercado.

Na mesma linha de pensamento, Kotler e Armstrong (1998) consideram que as empresas ganham vantagem competitiva ao planejarem ofertas que satisfaçam as cinco necessidades do consumidor. 
Segundo Silva e Saraiva (2012) é imprescindível conhecer o cliente, distinguindo as suas características e identificando as suas necessidades e vontades. Com este conhecimento é possível gerar proximidade, conquistando a sua confiança e consequente, fidelizando-o. É primordial que além de satisfeito, o cliente sinta novamente o desejo pelo produto ou serviço.

De acordo às variáveis apresentadas foram identificadas as principais características que influenciam os consumidores na escolha de um salão de beleza. Dos fatores investigados, os mais citados foram: confiança na habilidade do profissional e higiene. Em relação à estrutura física, observou-se que os clientes conferem maior importância a aspectos como higiene e limpeza, estacionamento e aparência dos equipamentos.

Fica claro que, no nicho de salões de beleza faz-se necessário adotar estratégias que acrescentem valores aos serviços prestados, ou seja, não só a qualidade dos serviços, mas também a qualidade do ambiente de trabalho deve ser considerada. Dessa forma, as necessidades do cliente serão satisfeitas.

Durante a coleta alguns entrevistados apresentaram dificuldade com relação à interpretação do questionário, esse fator reduziu significativamente a quantidade de respostas.

A limitação desse estudo indica que a amostra não foi selecionada aleatoriamente, mas por conveniência. Mesmo assim, trata-se de uma contribuição significativa para o salão investigado, uma vez que revela o que o seu público mais valoriza.

\section{Considerações finais}

Ao considerar o bloco relacionado à estrutura do salão, conclui-se que o conforto é um forte fator de qualidade, por isso itens como estacionamento e entretenimento são importantes, principalmente sob a ótica de que para realizar alguns procedimentos, os clientes podem passar várias horas no local.

Esses itens são considerados benefícios implícitos, que o cliente avalia e adquire juntamente ao produto principal. "Um serviço consiste de um pacote de benefícios implícitos e explícitos, executado dentro de instalações de suporte e utilizando-se de bens facilitadores" (FITZSIMMONS; FITZSIMMONS, 2000, p. 43 apud TINOCO; RIBEIRO, 2007).

Em relação aos atributos de qualidade dos funcionários, pode-se considerar primordial o uso de uniformes, a constante atualização de tendências e a experiência profissional, isto porque o cliente espera que seus desejos e exigências sejam atendidos pela equipe.

Para Silva e Saraiva (2012) a satisfação é objeto resultante principalmente da Gestão da Qualidade, no que se refere à melhorar a experiência do cliente, por meio do aperfeiçoamento contínuo dos produtos, serviços e processos fornecidos.

No que tange a interação funcionário/cliente, destaca-se como fator determinante na escolha do salão de beleza que os funcionários estejam atentos às suas necessidades, sejam discretos e estejam dispostos a esclarecer todas as dúvidas em relação aos procedimentos. Em uma área de intenso contato pessoal e grande intimidade como um salão de beleza, é indispensável uma interação social próxima e amigável entre cliente e funcionário.

Ribeiro; Thiesen e Tinoco (2012) certificam que em empresas onde o nível de interação funcionário-clientes é alto, como em salões de beleza, uma relação agradável viabiliza a confiança, lealdade e percepção de qualidade através da cumplicidade durante o contato prolongado funcionário-cliente. 
$\mathrm{Na}$ leitura do bloco referente à qualidade dos serviços ofertados, interpreta-se que as entrevistadas prezam por horários de atendimento convenientes e flexíveis, além de variedade nos serviços disponíveis. No mercado é preciso ofertar uma variedade de serviços que permita agradar e fidelizar clientes. O horário também é fator relevante porque o serviço estético impossibilita a realização de outras atividades. (RIBEIRO; THIESEN; TINOCO, 2012)

As tecnologias desenvolvidas e as grandes tendências disseminadas pela globalização, constroem uma ampla grade de procedimentos e métodos estéticos. Essa demanda torna a variedade de serviços prestados um fator decisivo no processo de escolha e percepção de qualidade por parte do consumidor. (TINOCO; RIBEIRO, 2007)

A partir desta pesquisa verificou-se que satisfação do cliente é um processo e não apenas um episódio isolado. "Valor percebido é uma construção cognitiva que requer um trade-off entre benefícios e sacrifícios". (BRANCO; RIBEIRO; TINOCO, 2010, p. 579) Por esse motivo o estudo deve ser considerado não apenas um levantamento de dados mas sim uma via para modificá-los, sendo ele uma fonte para o desenvolvimento de estratégias e um auxílio para a tomada de decisão de donos e administradores de salões de beleza, que busquem aprimorar a avaliação do serviço e, em decorrência, obter satisfação, lucros e fidelização de clientes.

\section{Referências}

BATESON, John; HOFFMAN, K. Douglas. Princípios de marketing de serviços: conceitos, estratégias e casos. São Paulo: Pioneira Thomson Learning, 2015.

BRANCO, Gabriela Musse; RIBEIRO, José Luis Duarte; TINOCO, Maria Auxiliadora Cannarozzo. Determinantes da satisfação e atributos da qualidade em serviços de hotelaria. Produção, v. 20, n. 4, p. 576588, out./dez. 2010.

FRANCA DE OLIVEIRA, Priscilla Galindo; COSTA DE MENDONÇA, José Ricardo. O Espaço Físico e a Formação das Impressões nas Organizações: integrando as dimensões instrumentalidade, estética e simbolismo sob a perspectiva dramatúrgica. Pesq. Anpad, set. 2008. Disponível em: <http://www.anpad.org.br/admin/pdf/EOR-B1478.pdf> Acesso em, 13 de outubro 2019.

GIL, Antônio Carlos. Métodos e técnicas de pesquisa social. 5. ed. São Paulo: Atlas, 1999.

KOTLER, Philip; ARMSTRONG, Gary. Princípios de marketing. 7 ed. Rio de Janeiro: Pearson Prentice Hall, 1998.

MARTINS, Cristina; VENÂNCIO, Daniella Macedo; FIATES, Gabriela Gonçalves Silveira; ROMAN, Darlan José; ERDMANN, Rolf Hermann. Gestão de serviços em salões de beleza: do diagnóstico à melhoria de qualidade. Revista Gepros, São Paulo, n. 3, 2014 . Disponível em: https://revista.feb.unesp.br/index.php/gepros/article/view/1047/553 Acesso em 29 de outubro de 2019.

RIBEIRO, José Luis Duarte; THIESEN, João Paulo Kappaun; TINOCO, Maria Auxiliadora Cannarozzo. Determinantes da satisfação e atributos da qualidade em serviços de salão de beleza. Produção, v. 23 , n. 3, p. 609-624, Porto Alegre, $2013 . \quad$ Disponível em: <http://www.scielo.br/pdf/prod/2012nahead/aop_t6_0002_0679.pdf> Acesso em 10 de dezembro de 2019.

ROS, Alan Roman. O crescimento da indústria de cosméticos no Brasil no século XXI. Curitiba, 2016. Disponível em: https://acervodigital.ufpr.br/bitstream/handle/1884/45699/ALAN\%20ROMAN\%20ROS.pdf?sequence=1\&is Allowed=y Acesso em 27 de novembro de 2019. 
SAAB, William George; GIMENEZ, Luiz Carlos; RIBEIRO, Rodrigo. Panorama do segmento de salões de beleza e barbearias. Rio de Janeiro, 2001. Disponível em: <https://web.bndes.gov.br/bib/jspui/bitstream/1408/17381/1/PRFol214532_Panorama\%20do\%20Segmento $\% 20 \mathrm{de} \% 20 \mathrm{Sal} \% \mathrm{C} 3 \%$ B5es $\% 20 \mathrm{de} \% 20$ Beleza $\% 20 \mathrm{e} \% 20$ Barbearias_compl_P_BD.pdf> Acesso em $27 \quad$ de novembro de 2019.

SILVA, Matheus Alberto Rodrigues. Alimentação fora do lar como um fenômeno de consumo pós-moderno: um estudo etnográfico. Dissertação (Mestrado em Administração) - Universidade Federal de Lavras, Lavras, 2011. Disponível em: http://repositorio.ufla.br/jspui/handle/1/2481

SILVA, Sónia; SARAIVA, Margarida. A Gestão da Qualidade como diferencial competitivo na Satisfação e Fidelização de clientes. III Encontro de Tróia 2012 - Qualidade, Investigação e Desenvolvimento, Évora Portugal, 2012. Disponível

em: https://dspace.uevora.pt/rdpc/bitstream/10174/5430/1/A $\% 20$ Gest $\%$ C3 $\%$ A3o $\% 20 \mathrm{da} \% 20$ Qualidade $\% 20$ como $\% 20$ diferencial $\% 20$ competitivo $\% 20$ na $\% 20$ Satisfa $\%$ C $3 \%$ A $7 \%$ C $3 \%$ A $30 \% 20 \mathrm{e} \% 20$ Fideliza $\%$ C $3 \%$ A $7 \%$ C $3 \%$ A $30 \%$ 20de\%20clientes_Silva.Saraiva.pdf. Acesso em 29 de outubro de 2019.

TINOCO, Maria Auxiliadora Cannarozzo; RIBEIRO, José Luis Duarte. Uma nova abordagem para a modelagem das relações entre os determinantes da satisfação dos clientes de serviços. Produção, v. 17, n. 3, p. 454-470, Set./Dez. 2007. 